\title{
Comparative Performance of Helicoverpa armigera (Lepidoptera: Noctuidae) on Chickpea and Faba Bean
}

\author{
Tarekegn Fite ${ }^{1}$, Tadele Tefera ${ }^{1}$, Mulugeta Negeri ${ }^{2}$, Tebekew Damte ${ }^{3}$, Waktole Sori ${ }^{4} \&$ William D. Hutchison ${ }^{5}$ \\ ${ }^{1}$ International Centre of Insect Physiology and Ecology (ICIPE), Nairobi, Kenya \\ ${ }^{2}$ Department of Plant Sciences, Ambo University College of Agriculture and Veterinary Science, Ambo, \\ Ethiopia \\ ${ }^{3}$ Debre Zeit Agricultural Research Center, Pulses, Oil Fibre Crops Research Team, Ethiopian Institute of \\ Agricultural Research, Debre Zeit, Ethiopia \\ ${ }^{4}$ Departement of Plant Science, Jimma University College of Agricultural and Veterinary Medicine, Jimma, \\ Ethiopia \\ ${ }^{5}$ Department of Entomology, University of Minnesota, St. Paul, U.S.A.
}

Correspondence: Tarekegn Fite, International Centre of Insect Physiology \& Ecology (ICIPE), Nairobi, Kenya. Tel: 251-910-865-935. E-mail: tfduressa@gmail.com

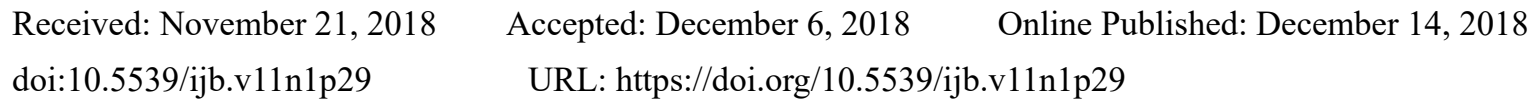

\begin{abstract}
Helicoverpa armigera Hübner (Lepidoptera: Noctuidae) is one of the most economically important agricultural pests of chickpea in Asia and Africa. Though most of the H. armigera biology was studied on chickpea, yet better understanding on fababean was still important. The present study was conducted to better understand the life cycle of $H$. armigera reared on chickpea and faba bean under laboratory conditions via the development of age-stage life tables. The results of life table study indicated that the highest survival rate was during the late larval instar on both hosts followed by early instars. High mortality was during prepupal stage on chickpea and during the $5^{\text {th }}$ larval instar on faba bean. Total larval period was 15.8 days on chickpea and 15.1 days on faba bean. Larvae reared on chickpea exhibited the longest (14.9 days) period of mean total pupal and pre-oviposition durations. Maximum fecundity and eggs viability were recorded from insect reared on chickpea. The current result revealed that chickpea was the more suitable host for reproduction and survival of $H$. armigera than faba bean under laboratory condition.
\end{abstract}

Keywords: Cicer Arietinum, Cotton Bollworm, IPM, Legumes, Life Tables, Vicia Faba

\section{Introduction}

The pod borer, Helicoverpa armigera Hübner (Lepidoptera: Noctuidae), is a polyphagous pest that infests over 200 plant species including valuable crops such as cotton, maize, tobacco, pigeonpea, chickpea, tomato, beans, peas, sorghum, sunflower and niger seeds (Damte et al., 2002; Sharma, 2005; Talekar et al., 2006; Cunningham \& Zalucki, 2014; Sedighe et al., 2017). It is highly dispersive and develops on various crops including conventional and genetically modified (Liu et al., 2004). The preference of $H$. armigera to feed on the harvestable parts of host plants, along with its high polyphagy, mobility, broad geographical coverage, migratory potential, facultative diapause and high fecundity contribute to its status as an important crop insect pest worldwide (Fitt, 1989; Ali et al., 2009; Luong et al., 2016). The insect is the most serious pest causing economic losses to the chickpea (Damte et al., 2002, Singh \& Yadav, 2006; Fite et al., 2018) and faba bean (Kemal \& Tibebu, 1994) in several countries. This insect causes chickpea yield reductions ranging from 40-50\% in India (Rai et al., 2003) and up to 32\% in Ethiopia (Tebkew, 2004), while it also causes 21\% losses to faba bean (Kemal \& Tibebu, 1994).

Various management actions have been undertaken to minimize the damage and yield losses caused by $H$. armigera to agricultural crops. In many parts of the world insecticides are used widely (Talekar et al., 2006); however, H. armigera can rapidly develop resistance to conventional insecticides (Ahmad et al., 1997; Kranthi et al., 2001; Ali et al., 2009; Reena et al., 2009). Thus, other pest management alternatives such as host plant resistance and biological control have been promoted, as part of Integrated Pest Management (IPM) programs have received increasing attention (Fathipou \& Sedaratian, 2013; Fite et al., 2018). Foundational to the development of 
IPM programs is a thorough understanding of pest species biology and ecology. The developmental, survivorship, reproduction and life table parameters of herbivorous insects are affected by temperature (Karimi-Malati et al., 2014; Soufbar et al., 2010; Karimi et al., 2012) and host plant quality (Naseri et al., 2011; Karimi et al., 2012). Life table analysis is a valuable tool for understanding how insect growth, developmental time, reproductive capacity, life expectancy and survival of insect populations contribute to overall population dynamics (Razmjou \& Naseri, 2014). Life table analysis on Helicoverpa sp. has been conducted using various host plants like cotton (Leonardo \& Miriam, 2002), soybean (Naseri et al., 2009), maize hybrids (Arghand et al., 2014), and vegetables such as asparagus (Jha et al., 2014). Since, chickpea and faba bean are two of the most preferred hosts by H. armigera, the construction of life tables and an improved knowledge of the life cycle will be valuable in developing improved IPM programs for these crops. Specifically, these data will be useful for forecasting pest incidence and the timing of insecticide applications to maintain low infestation levels. Moreover, efficient, economically feasible and ecologically viable IPM strategy begun from better understanding of $H$. armigera biology. However, there is no detailed work on the life table parameters of $H$. armigera on chickpea and faba bean plants. Hence, this study was carried out to evaluate comparative life table and life cycle of $H$. armigera on chickpea and faba bean at a constant temperature under laboratory conditions.

\section{Material and Methods}

\subsection{Description of Experimental Site}

The life cycle, and development of life tables of H. armigera were studied from September 2016 to April 2017, under laboratory conditions at Ambo University, which is located $\sim 114 \mathrm{~km}$ west of Addis Ababa.

\subsection{Host Plants}

Chickpea (Cicer arietinum L.) variety Habru, and faba bean (Vicia faba L.) variety Moti, seeds were obtained from the Ethiopian Institute of Agricultural Research (EIAR). The two crops were planted in plastic pots $(20 \mathrm{~cm}$ top, $13.5 \mathrm{~cm}$ base and $20 \mathrm{~cm}$ length). Approximately $3 \mathrm{Kg}$ of clay soil amended with $1 \mathrm{Kg}$ of sand were used for each pot and the pots consisted of two vigorous plants either chickpea or faba bean, at Ambo University in September 2016.

\subsection{Collection and Rearing of H. armigera}

To establish a stock culture of $H$. armigera, larvae were collected from unsprayed chickpea (Var. Ararti) field in Toke Kutaye district (located at 08o59. 321' N latitude; 037o47. 398' E longitude; altitude 1954 m.a.s.l). Field collected larvae were maintained on chickpea (Var. Ararti). A total of $200 \mathrm{H}$. armigera larvae were collected from the field; the first and second instars were arranged in groups of seven each, in plastic containers $(17 \mathrm{~cm}$ diameter, $6 \mathrm{~cm}$ depth with ventilation windows), each containing 10 larvae with chickpea leaf cuttings wrapped in water-soaked cotton to avoid leaf drying. The remaining third to fifth instars were reared individually in plastic vials $(6 \mathrm{~cm}$ diameter, $6.5 \mathrm{~cm}$ depth) by feeding on the chickpea reproductive stage (pods) for one generation. Host plant tissues were changed and rearing plastic containers and vials were cleaned every morning throughout the rearing period.

The colony was maintained at a constant temperature of $23 \pm 2 \mathrm{oC}, 50 \pm 5 \% \mathrm{RH}$ and 12:12 L:D photoperiod. Immediately after moth emergence, the F1 moths were released inside an oviposition cage $(50.5 \mathrm{~cm}$ diameter, 99 $\mathrm{cm}$ height) in pairs (one male and one female adult moth) containing 45 day old either chickpea or faba bean planted pots. Moth sex was identified based on their abdominal size and wing colour; female moths have brown wings and a relatively larger abdomen whereas male moths have greenish fore wing and are smaller in size compared to the female (Zenker et al., 2007). Then, the eggs of the F1 generations were collected using sterilized moist camel hairbrush from the respective hosts and preserved in Petri dish containing sterilized filter paper. Similar procedure was followed to get the eggs of F2 generations for life table and life cycle determination.

\subsection{Experiment 1: Life Table Determination}

For the life table study, 349 one-day old eggs collected from chickpea, and 279 eggs collected from faba bean were used to establish cohorts on each host plant. When hatched, seven groups of approx. 50 neonates each were transferred into plastic containers containing chickpea. Another five groups, each containing about 54 larvae were transferred to a plastic container $(17 \mathrm{~cm}$ diameter, $6 \mathrm{~cm}$ depth with ventilation windows) with faba bean. Each larval cohort was provided with fresh leaves; the petiole was wrapped in water-soaked cotton to maintain freshness until the $3^{\text {rd }}$ instar. Surviving instars were then reared individually and were maintained on the pods of chickpea and faba bean in a ventilated plastic vials $(6 \mathrm{~cm}$ diameter, $6.5 \mathrm{~cm}$ depth), to prevent cannibalism, following the procedure developed by Green et al. (2002) and Naseri et al. (2009). Each morning, larvae were checked for development to the next instar, and mortality; host plant pods were changed and the vials were also 
cleaned with $70 \%$ alcohol daily and allowed to dry before larvae were reintroduced to prevent possible microbial contamination. When larvae ceased feeding, they were provided with clean, dry pods for each host, to facilitate pupation. Daily observations data were then summarized for each cohort, including instar-specific larval survival, pupal survival, and the number of moths emerged.

\subsection{Experiment 2: Life Cycle Determination}

For life cycle study, newly hatched first instars were used. A total of 80 neonates (newly emerged) were used for chickpea with 8 replicates, each having 10 larvae. For faba bean, a total of 60 neonates were used with 6 replicates each having 10 larvae. Other larval rearing procedures were similar to those described for experiment 1. Upon emergence of adults, they were sexed as described above. Six pairs were released into oviposition cage (1pair/oviposition cage) as indicated above.

Each host was planted in pots placed inside cage for resting and egg lying. In addition, sterilized cotton soaked with $10 \%$ sucrose solution was put on sterilized petri dish in the cage that serves as food source for the adults. The eggs were counted daily and harvested as described above. Data were collected on durations of immature stages (eggs, larval and pupal durations), pre-oviposition, oviposition, post oviposition periods and adult longevity (female and male longevity). Similarly, pupal weight, fecundity, eggs viability and moth emergence were recorded from both hosts.

\section{Data Analysis}

The life table of $H$. armigera was constructed using the method and symbols proposed by Morris and Miller (1954) and Morris et al. (1963), with the addition of a column for the cumulative percent surviving (Carey, 2001). Symbols included: $\mathrm{x}$; age interval (development stage), $\mathrm{a}_{\mathrm{x}}$; number entering each class, $\mathrm{l}_{\mathrm{x}}$; number living/survivorship at the beginning of the stage noted in the $\mathrm{x}$ column, $\mathrm{d}_{\mathrm{x}}$; number dying within the age interval in the $\mathrm{x}$ column, $\mathrm{K}_{\mathrm{x}}$; mortality factor responsible for $\mathrm{d}_{\mathrm{x}}, 100 \mathrm{q}_{\mathrm{x}}$; percent mortality based on $\mathrm{l}_{\mathrm{x}}$ (i.e., $100 \mathrm{q}_{\mathrm{x}}=$ $\left.\left(d_{x} .100\right) / l_{x}\right), 100 r_{x}$; cumulative percent surviving. $F_{x}$; eggs produced at each stage, expected number of daughters at age $\mathrm{x}\left(\mathrm{m}_{\mathrm{x}}\right)$ were calculated according to Carey $(2001)$, and net reproductive rate $\left(\mathrm{Ro}=\sum 1_{\mathrm{x}} \mathrm{m}_{\mathrm{x}}\right)$ was estimated (Birch, 1948; Price, 1984; Southwood \& Henderson, 2000).

Life cycle parameters such as the duration of eggs, larval instars, pre-pupal, and pupae, as well as pupal weight, adult moth emergence (pre-oviposition, oviposition and post-oviposition), fecundity, moth emergence, and adult longevity of $H$. armigera reared on chickpea and faba bean were analysed using one-way ANOVA using the statistical software SAS packages to find out similarities and significant differences. Statistical differences among the means were assessed using the Tukeys test (at $\alpha=0.05$ ).

\section{Results}

\subsection{Experiment 1. Life Table Analysis}

\section{Mortality}

Higher egg mortality was recorded from chickpea (13.46\%) (Table 1) compared to faba bean $(10.39 \%)$ (Table 2). The mortality of larval instars ranged from 4.54 to $10.29 \%$ on chickpea and 6.92 to $20.62 \%$ on faba bean (Table 2). High larval mortality was observed on chickpea during third instar larvae; however, it was observed during fifth instar larvae on faba bean. Prepupal stage was the most vulnerable stage to natural death on chickpea followed by the pupal stage (Table 1).

Survival rates

The lowest survival rates of pupae were observed when reared on faba bean (0.36) and on chickpea (0.47). The highest survival rate was for the first instar larvae reared on faba bean (0.89) and on chickpea (0.86) (Tables $1 \&$ 2).

For both hosts the maximum and minimum survival rates were observed during the first and fifth larval instars. Both hosts have the highest survival rate during the early (first to third instars) larval instars than during late instars (fourth to fifth instars) (Tables $1 \& 2$ ). 
Table 1. Life table of $H$. armigera reared on chickpea under laboratory condition $\left(23 \pm 2{ }^{\circ} \mathrm{C}, 50 \pm 5 \%, 12: 12 \mathrm{~L}: \mathrm{D}\right)$, 2016/2017

\begin{tabular}{|c|c|c|c|c|c|c|c|c|}
\hline $\mathrm{X}$ & $\mathrm{ax}$ & $\mathrm{dx}$ & $100 \mathrm{qx}$ & $1 \mathrm{x}$ & Fx & $\mathrm{mx}$ & $1 \mathrm{xmx}$ & $\mathrm{Kx}(\log 1 \mathrm{x})$ \\
\hline Eggs & 349 & 47 & 13.47 & 1 & & & & 0.000 \\
\hline First instar & 302 & 16 & 5.29 & 0.86 & & & & 0.065 \\
\hline Second instar & 286 & 14 & 4.89 & 0.81 & & & & 0.091 \\
\hline Third instar & 272 & 28 & 10.29 & 0.77 & & & & 0.113 \\
\hline Average early instars & 286.6 & 29 & 6.82 & 0.81 & & & & 0.089 \\
\hline Fourth instar & 244 & 24 & 9.83 & 0.69 & & & & 0.161 \\
\hline Fifth instar & 220 & 10 & 4.54 & 0.63 & & & & 0.200 \\
\hline Average late instars & 232 & 17 & 7.18 & 0.66 & & & & 0.180 \\
\hline Prepupa & 210 & 44 & 20.95 & 0.60 & & & & 0.221 \\
\hline Pupa & 166 & 27 & 16.26 & 0.47 & & & & 0.327 \\
\hline \multirow[t]{2}{*}{ Adult (F) } & 65 & & & & 7,605 & 117 & 162.63 & \\
\hline & & & & & & & & $\mathrm{K}=1.178$ \\
\hline
\end{tabular}

Note: $\mathrm{x}$ - age class or developmental stages; $\mathrm{a}_{\mathrm{x}}$ - number entering each class; $\mathrm{d}_{\mathrm{x}}$ - number dying during $\mathrm{x} ; 100 \mathrm{q}_{\mathrm{x}}-\mathrm{dx}$ as a percentage of ax; $1_{x^{-}}$survival rate within $\mathrm{x} ; \mathrm{F}_{\mathrm{x}}$ - Eggs produced at each stage; $\mathrm{m}_{\mathrm{x}}$-Eggs produced per surviving individual at each stage (i. e., fecundity rate); $1_{x} m_{x}$-Eggs produced per original individual at each stage (i.e., the mean number of female offspring produced by females in an age class); $\mathrm{K}_{\mathrm{x}}$-the difference between successive values of $l_{x}$.

Table 2. Life table of $H$. armigera reared on fababean under laboratory condition $\left(23 \pm 2{ }^{\circ} \mathrm{C}, 50 \pm 5 \% \mathrm{RH}, 12: 12 \mathrm{~L}\right.$ : D photoperiod), 2016/2017

\begin{tabular}{|c|c|c|c|c|c|c|c|c|}
\hline $\mathrm{x}$ & ax & $\mathrm{dx}$ & $100 \mathrm{qx}$ & $1 \mathrm{x}$ & Fx & $\mathrm{mx}$ & $1 \mathrm{xmx}$ & $\mathrm{Kx}(\log 1 \mathrm{x})$ \\
\hline Eggs & 279 & 29 & 10.39 & 1 & & & & 0.000 \\
\hline First instar & 250 & 19 & 7.6 & 0.89 & & & & 0.091 \\
\hline Second instar & 231 & 16 & 6.92 & 0.82 & & & & 0.086 \\
\hline Third instar & 215 & 21 & 9.76 & 0.77 & & & & 0.113 \\
\hline Average early instars & 232 & 18.6 & 8.09 & 0.82 & & & & 0.096 \\
\hline Fourth instar & 194 & 34 & 17.52 & 0.69 & & & & 0.161 \\
\hline Fifth instar & 160 & 33 & 20.62 & 0.57 & & & & 0.244 \\
\hline Average late instars & 177 & 33.5 & 19.07 & 0.63 & & & & 0.202 \\
\hline Prepupa & 127 & 25 & 19.68 & 0.45 & & & & 0.346 \\
\hline Pupa & 102 & 8 & 7.84 & 0.36 & & & & 0.443 \\
\hline \multirow[t]{2}{*}{ Adult (F) } & 59 & & & & 5398.5 & 91.5 & 86.01 & \\
\hline & & & & & & & & $\mathrm{K}=1.484$ \\
\hline
\end{tabular}

Note: $x$ - age class or developmental stages; $a_{x}$ - number entering each class; $d_{x}-$ number dying during $x ; 100 q_{x}-d x$ as a percentage of ax; $1_{x^{-}}$survival rate within $\mathrm{x} ; \mathrm{F}_{\mathrm{x}^{-}}$Eggs produced at each stage; $\mathrm{m}_{\mathrm{x}}$-Eggs produced per surviving individual at each stage (i. e., fecundity rate); $1_{x} m_{x}$-Eggs produced per original individual at each stage (i.e., The mean number of female offspring produced by females in an age class); $\mathrm{K}_{\mathrm{x}}$-the difference between successive values of $l_{x}$.

\section{Reproductive potential}

On average 117 eggs/female was recorded from females reared on chickpea compared to females reared on faba bean, 91.5 eggs/female (Table 1 and Table 2). Similarly, the net reproductive rate (Ro) was indicated that the population $H$. armigera can increase each generation; 162.63 on chickpea and 86.01 on faba bean (Table 1).

\subsection{Experiment 2. Life Cycle Parameters}

Eggs and larval instars

It took an average of 4 days on chickpea and 3 days of incubation period for faba bean (Figure 1). The eggs remained yellow coloured on the average for 1.5 day, brown coloured for 2 days and black coloured for 1.6 days. 


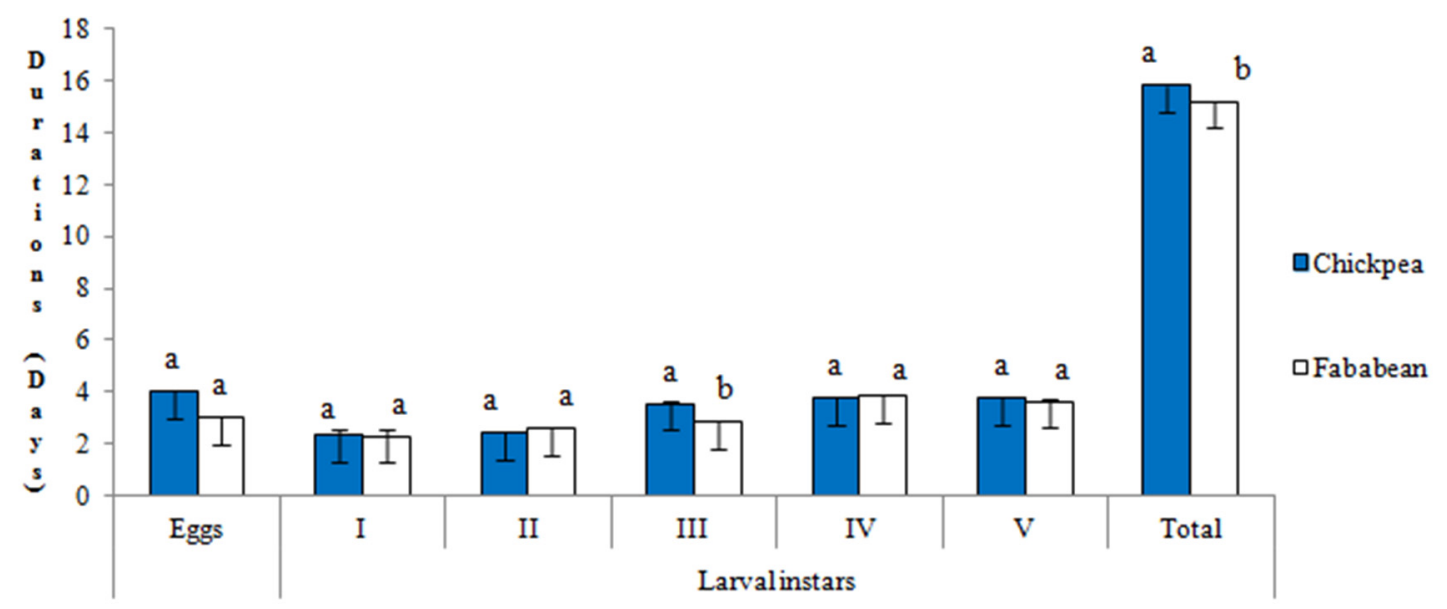

Figure 1. Eggs and Larval durations of $H$. armigera reared on chickpea and fababean under laboratory condition. Means sharing common letters above the bars are non-significantly different at 0.05 (Tukeys test) (Means $\pm \mathrm{SE}$ )

There were significant differences $(\mathrm{F}=28.58 ; \mathrm{df}=1,78 ; \mathrm{P}=<.0001)$ between third instar larvae in duration when reared on chickpea and faba bean (Figure 1); however, no significant differences were observed between the remaining larval instars in the two hosts. $H$. armigera reared on faba bean had significantly $(\mathrm{F}=6.02 ; \mathrm{df}=1,78$; $\mathrm{P}=0.0171$ ) shorter total durations than when reared on chickpea, with mean of 15.8 for faba bean and 15.2 for chickpea.

Pre-pupal \& pupal duration and pupal weight

There were significant differences between $H$. armigera reared on chickpea and faba bean in number of days required to prepupation $(\mathrm{F}=14.27 ; \mathrm{df}=1,78 ; \mathrm{P}=0.0004)$, pupation $(\mathrm{F}=3.67 ; \mathrm{df}=1,78 ; \mathrm{P}=0.043)$ and total number of days from prepupation to pupation (Figure 2). The number of days required for prepupation is shorter for the larvae reared on faba bean than for larvae reared on chickpea whilst it was the opposite for pupation period.

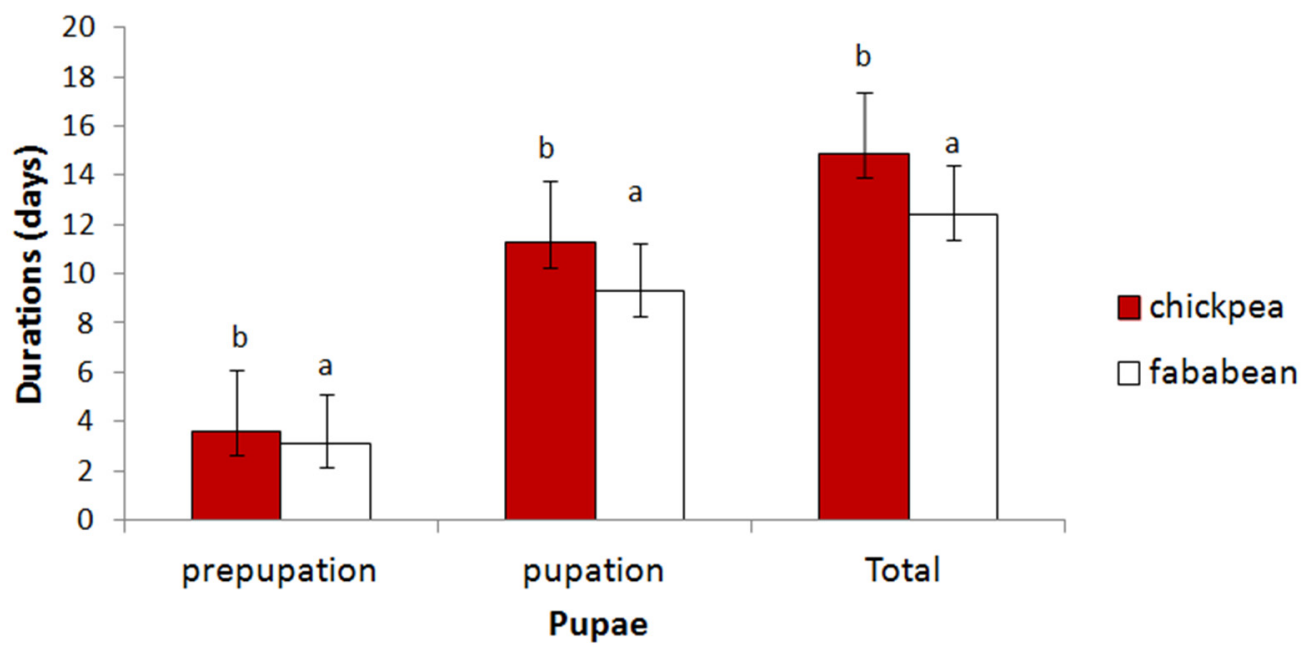

Figure 2. Duration (days) of prepupation, pupation and total pupal periods of H. armigera reared on chickpea and fababean. Means sharing common letters above the bars are non-significantly different at 0.05 (Tukeys test) (Means $\pm \mathrm{SE}$ )

There were no significant differences in pupal weight between larvae reared on chickpea and faba bean $(\mathrm{F}=1.36$; $\mathrm{df}=1,7 ; \mathrm{P}=0.2969$ ) (Figure 3). 


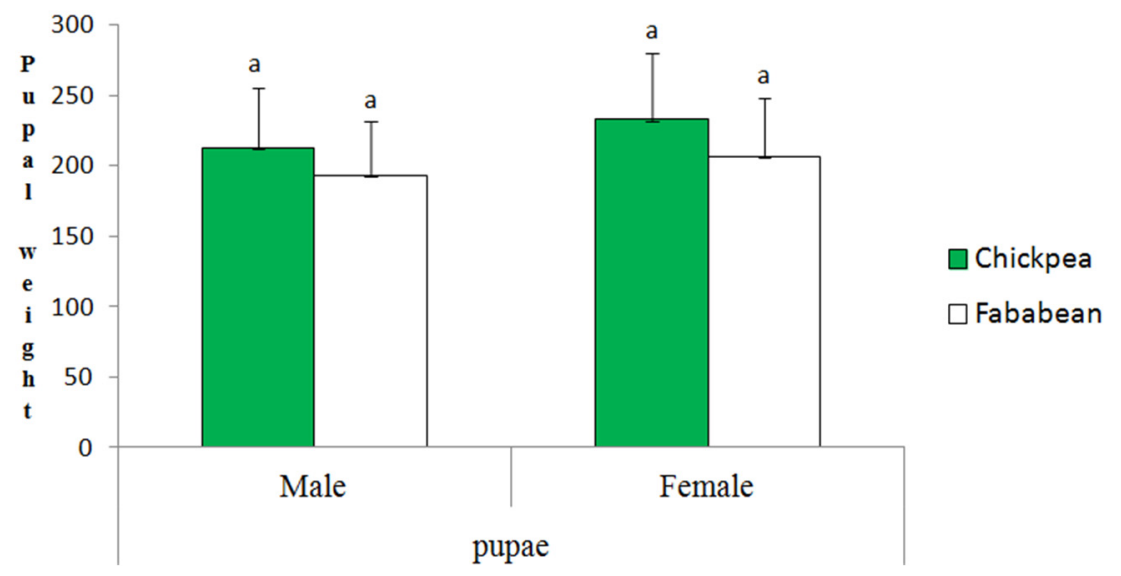

Figure 3. Pupal weight of $H$. armigera reared on chickpea and fababean. Means sharing common letters above the bars are non-significantly different at 0.05 (Tukeys test) (Means $\pm \mathrm{SE}$ )

\section{Adult moth performance}

Pre-oviposition, Oviposition and Post-oviposition durations

There were no significant differences in the number of days to preoviposition $(\mathrm{F}=4.62 ; \mathrm{df}=1,5 ; \mathrm{P}=0.0842)$, oviposition $(\mathrm{F}=0.87 ; \mathrm{df}=1,5 ; \mathrm{p}=0.3939)$ and the post-oviposition $(\mathrm{F}=1.87 ; \mathrm{df}=1,5 ; \mathrm{P}=0.2956)$ period between adult females reared on chickpea and faba bean. However, females exhibited a longer preoviposition, duration's on chickpea than on faba bean (Figure 4).

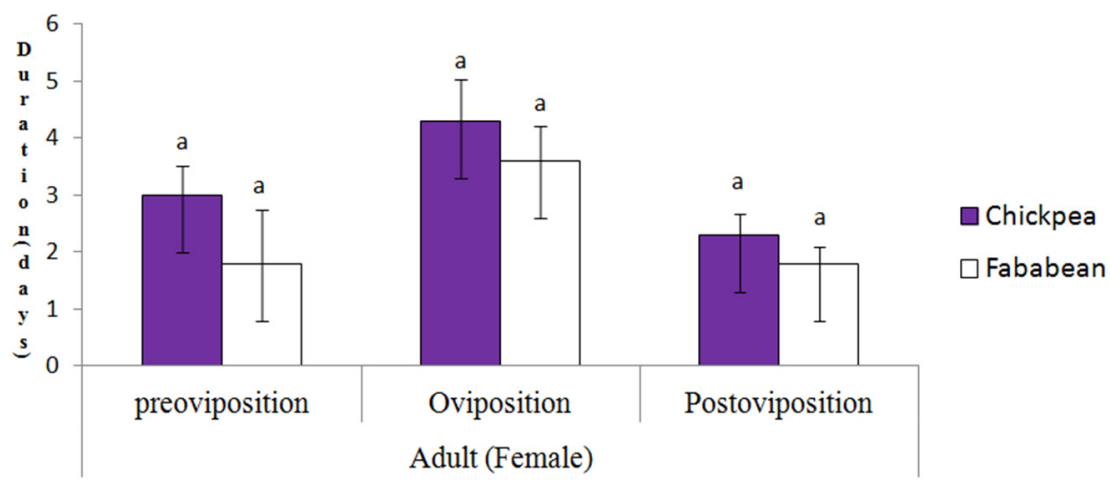

Figure 4. Duration of preoviposition, Oviposition, and postoviposition periods (days) of H. armigera reared on chickpea and fababean under laboratory condition. Means sharing common letters above the bars are non-significantly different at 0.05 (Tukeys test)

Fecundity

There were significant differences in mean fecundity between $H$. armigera females reared on chickpea and faba bean $(\mathrm{F}=634 ; \mathrm{df}=1,5 ; \mathrm{P}=0.03)$ and with egg viability $(\mathrm{F}=4.99 ; \mathrm{df}=1,5 ; \mathrm{P}=0.049)$ (Figure 5). The mean number of eggs from larvae reared on chickpea and laid on chickpea was 117 eggs/female, and higher than the mean number of eggs/female laid on faba bean (91 eggs/female) (Figure 5). Mean egg viability on chickpea was 95.83 fertile eggs/female compared to larvae reared on faba bean (67.17 fertile eggs/female) (Figure 5). 


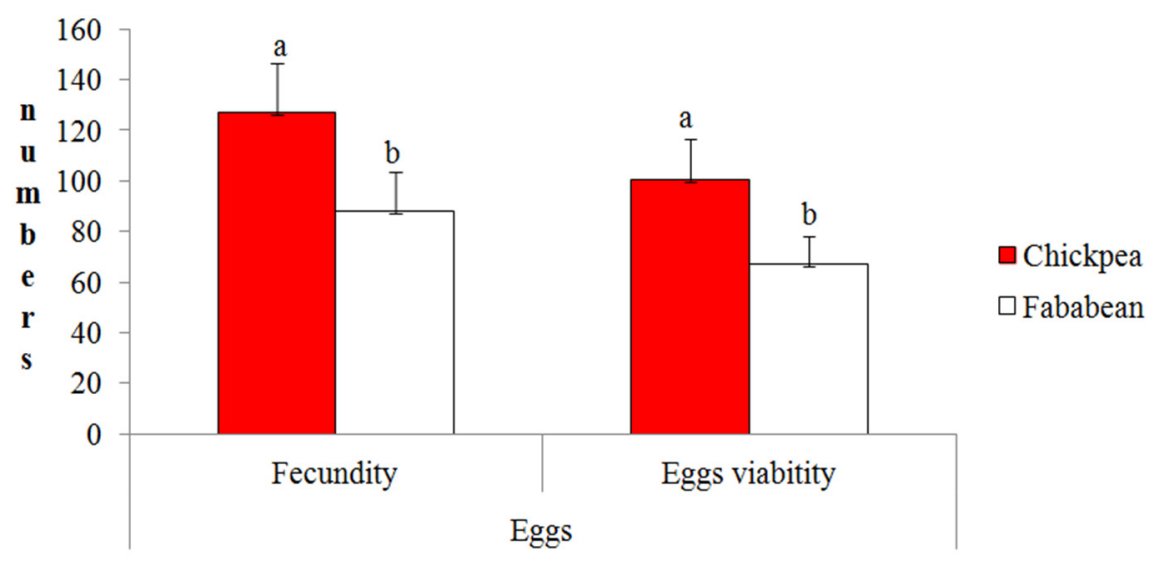

Figure 5. Fecundity and eggs viability reared on chickpea and fababean under laboratory condition. Means sharing common letters above the bars are non-significantly different at 0.05 (Tukeys test) (Means $\pm \mathrm{SE}$ )

Moth emergence and Adult longevity

Adult emergence and adult longevity (female; $\mathrm{F}=2.5 ; \mathrm{df}=1,5 ; \mathrm{p}=0.1747$ and male; $\mathrm{F}=2.14 ; \mathrm{df}=1,5 ; \mathrm{p}=0.2031$ ) were not affected by the host plants they were reared on (Figure 6).

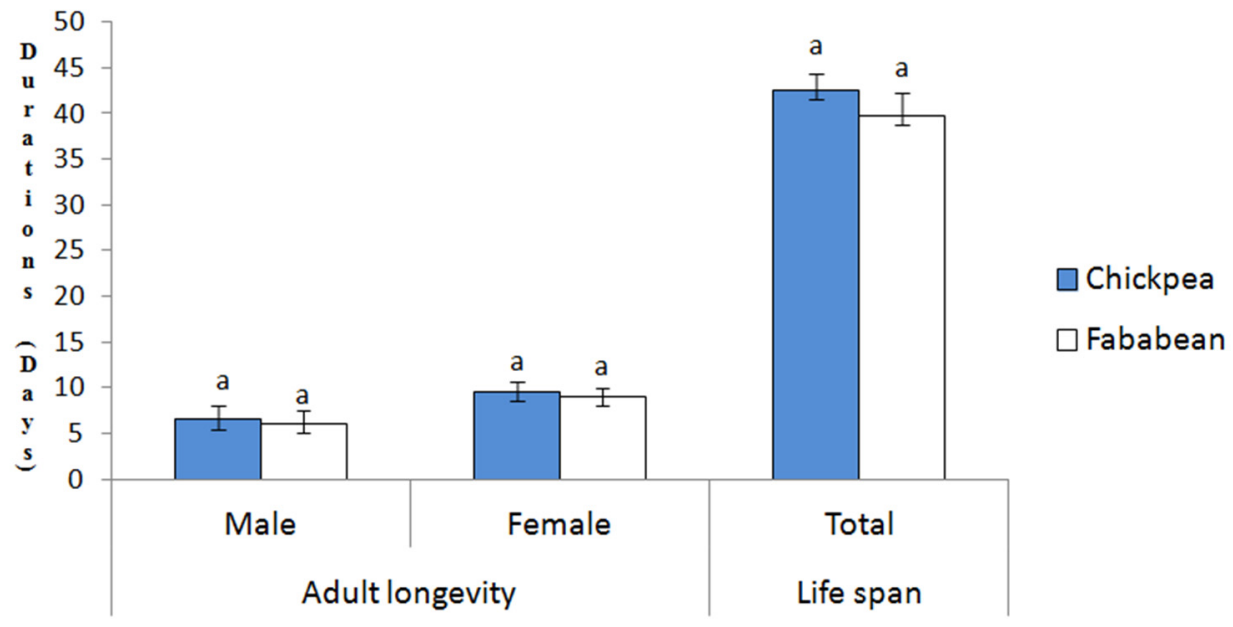

Figure 6. Adult longevity and the total life span (days) of $H$. armigera reared on chickpea and fababean under laboratory condition. Means sharing common letters above the bars are non-significantly different at 0.05

(Tukeys test) (Means $\pm \mathrm{SE}$ )

\section{Discussions}

The present study demonstrates that mortality and developmental time of various $H$. armigera larval instars varied among chickpea and faba bean. Differences in female pre-oviposition period and fecundity were also observed between the two host plants.

Relatively, lower egg mortality was observed on faba bean (10.4\%) than on chickpea (13.4\%), although this effect was not statistically significant. The variations in eggs mortality may be related to host plants because every host plants (parts) have its own physical and chemical characteristics that either harbour the egg density or deter female adults from oviposition. Several studies have reported that the physical and chemical characteristic of the leaves of the host plants may influence egg survival (Hilker \& Meiners, 2006; Muller \& Rosenberger, 2006; De Sibio \& Rossi, 2012; D'Costa et al., 2013). Fefelova \& Frolov (2008) also reported that an egg mortality of H. armigera was varied from 23 to $55 \%$ when reared on maize. Furthermore, the probability of egg death or/and survival may also depend on its location on the host plants or affected by the ovicidal substances produced by these host plants in response to adult oviposition. Similarly, Kyi et al. (1991) found that an attributed of 5-6\% egg loss in H. armigera 
were due to changing leaf orientation (i.e. host plant effects) and plants warned by egg deposition start to prepare certain defensive mechanisms against feeding larvae even before larval hatching (Beyaert et al., 2012; Fatouros et al., 2012; Geiselhardt et al., 2013; Pashalidou et al., 2013). In addition to host plant effect, the varying impact on eggs mortality may arise due to abiotic factors and natural egg unviability. In study conducted by Kumar et al. (2009) high egg mortality of $H$. armigera was correlated with abiotic factors and egg unviability. Other previous study also determined that temperature as the most basic determinant of the biology of $H$. armigera (Mironidis \& Soultani, 2008; Mironidis, 2014) and Psylliodes chrysocephala (Mathiasen et al., 2015).

By contrast, for both hosts the highest larval survival rate was observed for the early instars (I-III), specifically during the 1 st instars followed by the 2 nd instars, on both hosts. This indicated that, the mean average value of real mortality (100rx) of $H$. armigera was high during late (IV-V) instars on both hosts and this can be an illustration for an increasing mortality rate with larval age which arises due to the insect physiological changes in preparation for pupation and other unknown factors. Hogg \& Nordhein (1983) investigated an increasing mortality rate of Heliothis spp with age however, Kyi et al. (1991); Zalucki et al. (2002) \& Perovic et al. (2008) reported high mortality of $H$. armigera larvae during the first instar (i.e. early instars), under field condition. However, in the current study, mortality rates were much lower during late larval instar than early instar for both hosts, of course in our experiment natural enemies and abiotic factors have been excluded.

Comparing the larval survival rate, chickpea was more sustained the survival of instars of $H$. armigera. Relatively, the high survival rate of $H$. armigera instars on chickpea may be arising due to the high suitability of chickpea in supporting the entire life cycle of the insect, perhaps eggs to adults (Zalucki et al., 2002; Matheus et al., 2017).

In studies conducted recently by Reigada et al. (2016), soybean and cotton (Gomes et al., 2017) they reported that soybean, cotton and cowpea as the most suitable hosts sustaining the survival and reproduction of $H$. armigera, having similar values with artificial diets. Abbasi et al. (2007) also investigated varied larval mortality with little significant differences on a tapioca-based artificial diet in their study. Similarly, the report by Liu et al. (2004) concur with our results who found high mortality of $H$. armigera larval instars when reared on hot pepper (Capsicum frutescens L.) and tomato (Lycopersicon esculentum Mill.) in comparison to other host plants examined in their study. With regard to reproductive parameters greater fecundity was found on chickpea than on faba bean. According to the present result, females reared as larvae on chickpea had a higher rate of fecundity and fertility than those reared on faba bean, which suggested that chickpea was more suitable to $H$. armigera as compared with faba bean.

In the present investigation, the fifth larval instar, prepupal and pupal stages were more vulnerable to natural mortality when reared on both chickpea and faba bean. Such stage vulnerability under laboratory condition may be due to abiotic factors such as; temperature, relative humidity, photoperiods and unknown factors. As indicated the fifth larval stage is proceeding to the prepupal and further pupal stage, during which there is a complete physiological change to the stage and that determine the subsequent life stage. It was known that in insect biology; pupal stage is the stage at which the insect undergoes complete metamorphosis, diapauses which is dependent on the temperature and photoperiods (Kurban et al., 2005) and temperature positively affected the entire life cycle of insects as like in butterflies (Radchuk et al., 2013). Previous studies also have shown that the presence of immature stages of $H$. armigera on various hosts was no to mean the larvae will reach the adult stage on those species (Jallow \& Zalucki, 2003; Cunningham \& Zalucki, 2014).

Our result showed that the varying average incubation period on the two plant hosts are in agreement with the report found by Ali et al. (2009) who reported an average of $3.37 \pm 0.09$ days for $H$. armigera. Regarding the results of larval and Pre-pupational durations these developmental stages of $H$. armigera under laboratory conditions were related with the host plants so far used in insect rearing. The developmental stage of $H$. armigera reared on Soy bean varieties (Amer \& El-Sayed, 2014), Plutella xylostella on Brassica genotypes (Nikooei et al., 2015 ) and Tuta absoluta on tomato (Gharekhani \& Salek-Ebrahimi, 2014) was affected by the host plants on which they have been reared. Jallow et al. (2001) also reported larval durations of H. armigera reared on pepper (20.17 days), eggplant (19.85 days), tomato (16.2 days), okra (14.76 days) and maize (14.50 days).

The pre-pupation and total pupal period were relatively longer than the report by Naseri et al., (2009) \& Arghand et al. (2014), who they found an average duration of 2.59 and 1.46 days when reared on soybean and corn hybrids, respectively. Arghand et al. (2014) was also in line with our finding, who reported varying pupal period of $H$. armigera reared on corn hybrid ranged from $12.95 \pm 0.33$ on SC700 to $13.35 \pm 0.23$ days on DC370. Shorter pupal duration of $H$. armigera on maize ( 9.5 days) and longer (12 days) on castor bean was also determined (Amer \& El-Sayed, 2014). Ali et al. (2009) also reported that, pupal stage took minimum of 10 and maximum 14 days period at $250 \mathrm{C}$ and $65 \% \mathrm{RH}$. As an indicator of insect fitness the pupal weight of both pupae (male and female pupae) 
produced by the larvae reared on chickpea were heavier than those reared from larvae on faba bean. This may be attributed to the better suitability and nutritional quality of chickpea for the growth and development of $H$. armigera (Razmjou et al., 2014). Arghand et al. (2014) found that higher pupal weight was found from corn hybrid (SC704) with compared to other hosts. In the current investigation the mean pre-oviposition, oviposition and post-oviposition period of $H$. armigera reared on chickpea was longer than on faba bean which suggested that, the reproduction parameters of $H$. armigera were affected by the two host plants implying; these two hosts plants were cofound plants by supporting the entire life cycle of $H$. armigera. Oviposition period was the longest period on both host plants, which is in consistent with the finding of Bhatt \& Patel (2001) who reported that the pre-oviposition, oviposition and post oviposition periods $H$. armigera on chickpea were $2.8,7.5$ and 1.1 days, respectively.

Eggs viability also follow similar trend with fecundity in that higher eggs viability was observed when the adult female moths were laid eggs on chickpea, which enforces the suitability and nutritious of chickpea for $H$. armigera in comparison to faba bean. Adult emergence and longevity of $H$. armigera were not influenced by these two hosts.

Razmjou et al. (2014) and Amer \& El-Sayed (2014) reported that among the various host plants tested, fecundity was highest on chickpea and lowest on tomato. Females emerging from the larvae that fed on common bean laid more eggs than the larvae reared on other host plants examined (Liu et al., 2004), and high performance of $H$. armigera on chickpea cultivars in relation to other hosts (Hemati et al., 2013).

\section{Conclusion}

As a conclusion, the results of the current study from both life table and life cycle parameters of laboratory reared $H$. armigera suggest that chickpea were more suitable than faba bean. Understanding the basic knowledge of such economically important chickpea insect pests like H. armigera on their major hosts and related crop is essential in better understanding the insect dynamics, to predict more reliable insect development stage for management methods, to design sustainable integrated pest management and ease of its implementation under field condition. In the absence of chickpea or faba bean $H$. armigera would survive and reproduce on either and cause an outbreak on the subsequent crop. Future research directions should focus on investigation of key mortality factors and biological performance of $H$. armigera on other alternative hosts under both laboratory and field conditions are required.

\section{Acknowledgments}

This study was supported by the USAID Feed the Future IPM Innovation Lab, Virginia Tech, Cooperative Agreement No. AID-OAA-L-15-00001. Tarekegn Fite is an icipe student supported by the USAID Feed the Future IPM Innovation Lab, Virginia Tech, under the provision of Rice, Maize, and Chickpea IPM Project for East Africa. We also gratefully acknowledge the financial support by the UK's Department for International Development (DFID); Swedish International Development Cooperation Agency (Sida); the Swiss Agency for Development and Cooperation (SDC); and the Kenyan Government. The views expressed herein do not necessarily reflect the official opinion of the donors. We also wish to forward our thankful appreciation to Plant Science Laboratory Technicians of Ambo University, College of Agriculture and Veterinary sciences for technical support especially Mr. Fula'a Galana and Habtamu Haile.

\section{Conflict of interests}

The authors declare that there is no conflict of interests regarding the publication of this paper.

\section{References}

Abbasi, B., Ahmed, K., Khalique, F., Ayub, N., Liu, H., Kazmi, S., \& Aftab, M. (2007). Rearing the cotton bollworm, Helicoverpa armigera, on a tapioca-based artificial diet. Journal of Insect Science, 7, 7-35.

Ahmad, M., Arif, M. I., \& Attique, M. R. (1997). Pyrethroids resistance of Helicoverpa armigera (Hübner) (Lepidoptera: Noctuidae) in Pakistan. Bulletin of Entomology Research, 33, 173-178.

Ali, A., Choudhury, R. A., Ahmad, Z., Rahman, F., ... \& Ahmad, S. K. (2009). Some biological characteristics of Helicoverpa armigera on chickpea. Tunisian Journal of Plant Protection, 4(1), 99-106.

Amer, A. E. A., \& El-Sayed, A. A. A. (2014). Effect of different host plants and artificial diet on Helicoverpa armigera (Hübner) (Lepidoptera: Noctuidae) development and Growth Index. Journal of Entomology.

Arghand, B., Naseri, J., Razmjou, H. M., \& Rahimi, F. N. (2014). Comparative biological parameters of the cotton bollworm, Helicoverpa armigera (Lepidoptera: Noctuidae) on various corn hybrids. Journal of Entomological Society of Iran, 34(2), 33-35. 
Beyaert, I. et al. (2012). Can insect egg deposition 'warn' a plant of future feeding damage by herbivorous larvae? Proc. R. Soc, 279, 101-8.

Bhatt, N., \& Patel, R. (2001). Biology of chickpea pod borer, Helicoverpa armigera Hübner (Lepidoptera: Noctuidae). Indian Journal of Entomology, 70(2), 118-122.

Birch, L. C. (1948). The intrinsic rate of natural increase of an insect population. Journal of Animal Ecology, 17, $15-26$.

Bisane, K. D., Khande, D. M., Bhamare, V. K., \& Katole, S. R. (2009). Life table studies of Helicoverpa armigera (Hübner) on chickpea. International Journal of Plant Protection, 1(2), 54-58.

Carey, J. R. (2001). Applied demography for biologists with especial emphasis on insects (p. 205). New York, NY: Oxford Univ Press.

Cunningham, J. P., \& Zalucki, M. P. (2014). Understanding Heliothine (Lepidoptera: Heliothinae) pests: What is a host plant? Journal of Economic Entomology, 107, 881-896.

D’Costa, L., Koricheva, J., Straw, N., \& Simmonds, M. S. J. (2013). Oviposition patterns and larval damage by the invasive horse-chestnut leaf miner Cameraria ohridella on different species of Aesculus. Journal of Ecological Entomology, 38, 456-462.

Damte, T., Tesfaye, A., \& Dejen, A. (2002). Potentials for botanicals in controlling the African bollworm. In: the Proceedings of the National Work shop on African bollworm management in Ethiopia: Status and Need, April 17-19, 2002, Ambo, Ethiopia, pp: 106-114.

De Sibio, P. R., \& Rossi, M. N. (2012). Oviposition of a leaf-miner on Erythroxylum tortuosum (Erythroxylaceae) leaves: Hierarchical variation of physical leaf traits. Australian Journal of Botany, 60, 136-142.

Fathipour, Y., \& Sedaratian, A. (2013). Integrated management of Helicoverpa armigera in soybean cropping systems. In H. El-Shemy (Ed.), Soybean-Pest Resistance (pp. 231-280). Retrieved from http://www.intechopen.com/download/get/type/pdfs/id/42604

Fatouros, N. E. et al. (2012). Plant volatiles induced by herbivore egg deposition affect insects of different trophic levels. PLOS ONE, 7, e43607.

Fefelova, Y. A., \& Frolov, A. N. (2008). Distribution and mortality of corn earworm (Helicoverpa armigera, Lepidoptera: Noctuidae) on maize plants in Krasnodar Territory. Entomological Review, 88, 480.

Fite, T., Tefera, T., Negeri, M., Damte, T., \& Sori, W. (2018). Management of Helicoverpa armigera (Lepidoptera: Noctuidae) by Nutritional Indices and Botanical Extracts of Millettia ferruginea and Azadirachta indica. Advances in Entomology, 6, 235-255.

Fitt, G. P. (1989). The ecology of Heliothis species in relation to agroecosystems. Annual Review of Entomology, $34,17-52$.

Geiselhardt, S. et al. (2013). Egg laying of Cabbage White Butterfly (Pieris brassicae) on Arabidopsis thaliana affects subsequent performance of the larvae. PLOS ONE, 8, e59661.

Gharekhani, G. H., \& Salek-Ebrahimi, H. (2014). Life table parameters of Tuta absoluta (Lepidoptera: Gelechiidae) on different varieties of tomato. Journal of Economic Entomology, 107(5), 1765-1770.

Gomes, E. S., Santos, V., \& Avila, C. J. (2017). Biology and fertility life table of Helicoverpa armigera (Lepidoptera: Noctuidae) in different hosts. Journal of Applied Entomology. https://doi.org/10.1111/ens.12267

Green, P. W. C., Stevenson, P. C., Simmonds, M. S. J., \& Sharma, H. C. (2002). Can larvae of the pod borer, Helicoverpa armigera (Lepidopter: Noctuidae), select between wild and cultivated pigeon pea, Cajanus sp. (Fabaceae)? Bulletin of Entomological Research, 92(1), 45-51.

Hemati, S. A., Naseri, B., \& Razmjou, J. (2013). Reproductive performance and growth indices of the cotton bollworm, Helicoverpa armigera (Lepidoptera: Noctuidae) on various host plants. Crop Protection, 2(2), 193-208.

Hilker, M., \& Meiners, T. (2006). Early herbivore alert, insect eggs induce plant defense. Journal of Chemical Ecology, 32, 1379-1396.

Hogg, D. B., \& Nordheim, E. V. (1983). Age-Specific survivorship of Heliothis spp. population on cotton. Research in Population Ecology, 25, 280-297. 
Jallow, M. F. A., \& Zalucki, M. P. (2003). Relationship between oviposition preference and offspring performance in Australian Helicoverpa armigera (Hübner) (Lepidoptera: Noctuidae). Australian Journal of Entomology, 42, 343-348.

Jallow, M. F. A., Matsumura, M., \& Suzuki, Y. (2001), Oviposition preference and reproductive performance of Helicoverpa armigera (Hübner). Applied Entomology and Zoology, 36(4), 419-426.

Jha, R. K., Tuan, S. J., Chi, H., \& Tang L. C. (2014). Life table and consumption capacity of corn earworm, Helicoverpa armigera, fed asparagus, Asparagus officinalis. Insect Science, 14, 34.

Karimi, S., Fathipour, Y., Talebi, A. A., \& Naseri, B. (2012). Evaluation of canola cultivars for resistance of Helicoverpa armigera (Lepidoptera: Noctuidae) using demographic parameters. Journal of Economic Entomology, 105, 2172-2179.

Karimi-Malati, A., Fathipour, Y., Talebi, A. A., \& Bazoubandi, M. (2014). Life table parameters and survivorship of Spodoptera exigua (Hübner) (Lepidoptera: Noctuidae) at constant temperatures. Environmental Entomology, 43, 795-803.

Kemal, A., \& Tibebu, H. (1994). Research on insect pests of cool-season food legumes (pp. 367-396). In T. Asfaw, B. Geletu, M. C. Saxena, \& M. B. Solh (Eds.), Coolseason Food Legumes of Ethiopia. Proceeding of the first national cool-season food legumes review conference, 16-20 December 1993, Addis Ababa, Ethiopia. ICARDA/IAR. ICARDA, Syria.

Khanamani, M., Fathipour, Y., \& Hajiqanbar, H. (2013). Population growth response of Tetrany chusurticae to eggplant quality: Application of female age-specific and age-stage, two-sex life tables. International Journal of Acarology, 39, 638-648.

Kranthi, K. R., Jadhav, D. R., Wanjari, R. R., Kranthi, S., \& Rassell, D. A. (2001). Pyrethroid resistance and mechanisms of resistance in field strains of Helicoverpa armigera (Lepidoptera: Noctuidae). Journal of Economic Entomology, 94, 253-263.

Kumar, S., Saini, R. K., \& Ram, P. (2009). Natural mortality of Helicoverpa armigera (Hübner) eggs in the cotton ecosystem. Agricultural Science and Technology, 11, 17-25.

Kurban, A., Yoshida, H., Izumi, Y., Sonoda, S., \& Tsumuki, H. (2005). Pupal diapause of Helicoverpa armigera: Sensitive stage for photoperiodic induction. Applied Entomology and Zoology, 40, 457-460.

Kyi, A., Zalucki, M. P., \& Titmarsh, I. J. (1991). An experimental study of the early stage survival of Helicoverpa armigera (Lepidoptera: Noctuidae) on cotton. Bulletin of Entomology Research, 81, 263-271.

Leonardo, T. P., \& Miriam, E. P. (2002). Life Table of Cotton Bollworm, Helicoverpa armigera Hübner (Lepidoptera: Noctuidae) in Batac, Ilocos Norte, Philippines. Philippine. Journal of Science, 131(2), 75-89.

Liu, Z. D., Li, D. M., Gong, P. Y., \& Wu, K. J. (2004). Life table studies of the cotton bollworm, Helicoverpa armigera (Hübner) (Lepidoptera: Noctuidae), on different host plants. Journal of Environmental Entomology, 33(6), 1570-1576.

Luong, T. T. A., Downes, S. J., Cribb, B., Perkins, L. E., \& Zalucki, M. P. (2016). Oviposition site selection and survival of susceptible and resistant larvae of Helicoverpa armigera (Lepidoptera: Noctuidae) on $\mathrm{Bt}$ and non-Bt cotton. Bulletin of Entomological Research, 106, 710-717.

Matheus, L. S. N., Lara, L. F., Rízia da, S. A., Janayne, M. R., ... \& Karina, C. A. G. (2017). Biology of Helicoverpa armigera (Hübner) (Lepidoptera: Noctuidae) Rearing on Artificial or Natural Diet in Laboratory. Journal of Entomology, 14, 168-175.

Mathiasen, H., Sorensen, H., Bligaard, J., \& Esbjerg, P. (2015). Effect of temperature on reproduction and embryonic development of the cabbage stem flea beetle, Psylliodes chrysocephala L., (Coleoptera: Chrysomelidae). Journal of Applied Entomology.

Mironidis, G. K. (2014). Development, survivorship and reproduction of Helicoverpa armigera (Lepidoptera: Noctuidae) under fluctuating temperatures. Bulletin Entomology Research, 104(6), 751-64.

Mironidis, G. K., \& Soultani, M. S. (2008). Development, survivorship and reproduction of Helicoverpa armigera (Lepidoptera: Noctuidae) under constant and alternating temperatures. Journal of Environmental Entomology, 37(1), 16-28.

Morris, R. F. (1963). On the dynamics of epidemic spruce budworm populations. Entomological Society of Canada, 31, 332 . 
Morris, R. F., \& Miller, C. A. (1954). The development of life tables for the spruce budworm. Canadian Journal of Zoology, 32, 283-301.

Muller, C., \& Rosenberger, C. (2006). Different oviposition behaviour in Chrysomelid beetles, characterisation of the interface between oviposition secretion and the plant surface. Arthropod Structure and Development, 35, 197-205.

Naseri, B., Fathipour, Y., Moharramipour, S., \& Hosseininaveh, V. (2009). Comparative life history and fecundity of Helicoverpa armigera (Hübner) (Lepidoptera: Noctuidae) on different soybean varieties. Journal of Entomological Science, 12, 147-154.

Naseri, B., Fathipour, Y., Moharramipour, S., \& Hosseininaveh, V. (2011). Comparative reproductive performance of Helicoverpa armigera (Hübner) (Lepidoptera: Noctuidae) reared on thirteen soybean varieties. Agricultural Science and Technology, 13, 17-26.

Nikooei, M., Fathipour, Y., Jalali, J. M., Soufbaf, M., \& Soufbaf, M. (2015). How different genetically manipulated brassica genotypes affect life table parameters of Plutella xylostella (Lepidoptera: Plutellidae). Journal Economic Entomology, 108(2), 515-524.

Pashalidou, F. G., Lucas-Barbosa, D., Van Loon, J. J. A., Dicke, M., \& Fatouros, N. E. (2013). Phenotypic plasticity of plant response to herbivore eggs: Effects on resistance to caterpillars and plant development. Journal of Ecology, 94, 702-13.

Perovic, D. J., Johnson, M. L., Scholz, B., \& Zalucki, M. P. (2008). The mortality of Helicoverpa armigera (Hubner) (Lepidoptera: Noctuidae) neonate larvae in relation to drop-off and soil surface temperature: The dangers of bungy jumping. Australian Journal of Entomology, 47, 289-296.

Price, P. W. (1984). Insect Ecology. John Wiley and Sons, New York. Google Scholar.

Radchuk, V., Turlure, C., \& Schtickzelle, N. (2017). Each life stage matters: The importance of assessing the response to climate change over the complete life cycle in butterflies. Journal of Animal Ecology, 82, $275-285$.

Rai, D., Ujagir, R., \& Singh, R. K. (2003). The larval parasitization by Campoletis chlorideae Uchida (Hymenoptera: Ichneumonidae) of Helicoverpa armigera (Hübner) in pure chickpea crop at Pantnagar. Biological Control, 17, 81-83.

Razmjou, M., Naseri, J., Hemati, B., \& Ali, S. (2014). Comparative performance of the cotton bollworm, Helicoverpa armigera (Hübner) (Lepidoptera: Noctuidae) on various host plants. Journal of Insect Science, 87(1), 29-37.

Reena, S. K., Singh, B. K. S., \& Jamwal, B. S. (2009). Management of gram pod borer, Helicoverpa armigera (Hübner) by intercropping and monitoring through pheromone traps in chickpea. Karnataka Journal of Agricultural Science, 22(3), 524-526.

Reigada, C., Guimaraes, K. F., \& Parra, J. R. P. (2016). Relative fitness of Helicoverpa armigera (Lepidoptera: Noctuidae) on seven host plants: A Perspective for IPM in Brazil. Journal of Insect Science, 16(1), 3.

Sedighe, S. P., Fathipou, Y., \& Talebi, A. A. (2017). Evaluation of tomato cultivars to Helicoverpa armigera using two-sex life table parameters in laboratory. Journal of Asia-Pacific Entomology, 17(4), 837-844.

Sharma, H. C. (2005). Heliothis/Helicoverpa Management: Emerging trends and strategies for future research. New Delhi, India: Oxford and IBH Publishing Co.

Singh, S. S., \& Yadav, S. K. (2006). Evaluation of chickpea varieties for their resistance against gram pod borer, Helicoverpa armigera. Indian Journal of Entomology, 68(4), 321-324.

Soufbaf, M., Fathipour, Y., Karimzadeh, J., \& Zalucki, M. (2010). Bottom-up effect of different host plants on Plutella xylostella (Lepidoptera: Plutellidae): A life-table study on canola. Journal of Economical Entomology, 103, 2019-2027.

Southwood, T. R. E., \& Henderson, P. A. (2000). Ecological Methods (3rd ed.). Oxford: Black well Science.

Talekar, N. S., Opena, R. T., \& Hanson, P. (2006). Helicoverpa armigera management: A review of AVRDC's research on host plant resistance in tomato. Crop Protection, 25, 461-467.

Tebkew, D. (2004). Importance of pod borer, Helicoverpa armigera (Lepidoptera: Noctuidae). Integrated Pest Management Journal of Ethiopia, 8, 105-110. 
Zalucki, M. P., Clarke, A. R., \& Malcolm, S. B. (2002). Ecology and behaviour of first instar larval Lepidoptera. Annual Review of Entomology, 47, 361-393.

Zenker, M. M., Specht, A., \& Corseuil, E. (2007). Estágios imaturos de Spodoptera cosmioides (Walker) (Lepidoptera, Noctuidae). Revista Brasileira de Zoologia, 24, 99-107.

\section{Copyrights}

Copyright for this article is retained by the author(s), with first publication rights granted to the journal.

This is an open-access article distributed under the terms and conditions of the Creative Commons Attribution license (http://creativecommons.org/licenses/by/4.0/). 